\title{
DEVELOPMENT OF LIQUID INOCULANTS: AN INNOVATIVE AGRONOMIC PRACTICE FOR SUSTAINABLE AGRICULTURE
}

\author{
Jagjot Kaur $^{1}$, Gulab Pandove ${ }^{2 *}$, Madhurama Gangwar ${ }^{1}$, Sukhdeep Kaur Brar ${ }^{2}$ \\ ${ }^{1}$ Department of Microbiology, Punjab Agricultural University, Ludhiana, Punjab, India \\ ${ }^{2}$ Punjab Agricultural University, Regional Research Station, Bathinda, Punjab
}

Received - November 09, 2017; Revision - February 24, 2018; Accepted - May 21, 2018

Available Online - June 20, 2018

DOI: http://dx.doi.org/10.18006/2018.6(3).472.481

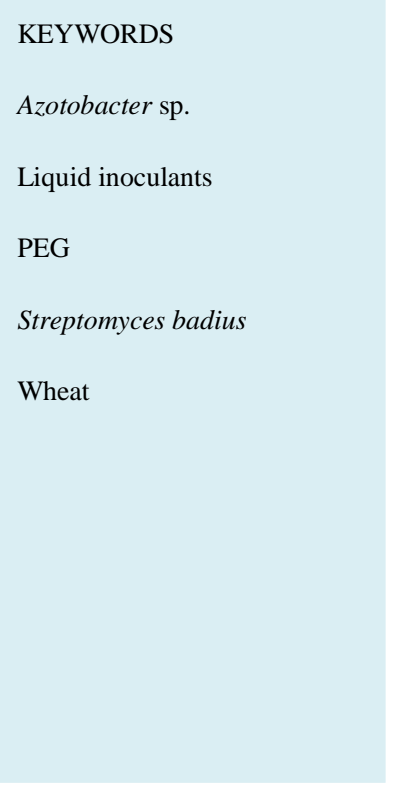

\begin{abstract}
The Present investigation was undertaken to develop liquid inoculants of Azotobacter sp. and Streptomyces badius and to evaluate its affect on yield attributes of wheat (Triticum aestivum L.) under field conditions. Both the cultures of Azotobacter sp. and Streptomyces badius were procured from the Department of Microbiology, Punjab Agricultural University, Ludhiana, Punjab and evaluated for their plant growth promoting traits. The quantity of IAA, phosphate solublization, gibberellic acid, ammonia production by Azotobacter sp. was $10.75 \mu \mathrm{g} / \mathrm{ml}, 21.74 \mu \mathrm{g} / 100 \mathrm{ml}, 77.86 \mu \mathrm{g} / \mathrm{ml}$ and $27.68 \mu \mathrm{mole} / \mathrm{ml}$ respectively and by Streptomyces badius was $13.39 \mu \mathrm{g} / \mathrm{ml}, 28.73 \mu \mathrm{g} / 100 \mathrm{ml}, 108.44 \mu \mathrm{g} / \mathrm{ml}$ and 32.48 $\mu \mathrm{mole} / \mathrm{ml}$ respectively. Further, siderophore production was exhibited by Streptomyces badius only. It produced $104.89 \mu \mathrm{g} / \mathrm{ml}$ of catechol type and $62.84 \mu \mathrm{g} / \mathrm{ml}$ of hydroxamate type siderophores. Both the cultures were also found positive for ACC-deaminase. Liquid inoculants of Azotobacter sp. and Streptomyces badius were formulated using $2 \%$ PEG in basal medium and showed maximum viability even after 180 days as compared to charcoal carrier based formulation both at room and refrigerated temperature. Further, the field experiment was conducted during winter (rabi) season of 2016-17 at Punjab Agricultural University, Regional Research Station, Bathinda, Punjab with three treatments viz. $\mathrm{RDF}, \mathrm{RDF}+$ Liquid inoculants of Azotobacter sp. and Streptomyces badius and: RDF + Charcoal carrier based inoculants of Azotobacter sp. and Streptomyces badius. This experiment was laid out in randomized complete block design and replicated thrice. The liquid inoculants as well as charcoal based
\end{abstract}

* Corresponding author

E-mail: gpandove@pau.edu (Gulab Pandove)

Peer review under responsibility of Journal of Experimental Biology and Agricultural Sciences.

Production and Hosting by Horizon Publisher India [HPI] (http://www.horizonpublisherindia.in/).

All rights reserved.
All the article published by Journal of Experimental Biology and Agricultural Sciences is licensed under a Creative Commons Attribution-NonCommercial 4.0 International License Based on a work at www.jebas.org.

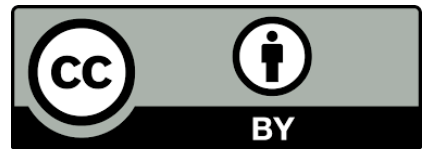


inoculants of Azotobacter sp. and Streptomyces badius were found superior in yield attributing characters over control. However, percentage increase in grain yield and biological yield was highest with liquid inoculants. This might be due to higher survival of Azotobacter sp. and Streptomyces badius in liquid formulation. Thus, it can be concluded that liquid inoculants of Azotobacter sp. and Streptomyces badius can enhance yield of wheat. This combination may be used as an efficient PGPR for wheat production.

\section{Introduction}

Microbial inoculants (bio-inoculants) are the mean of inoculation of one or more beneficial microbial strains or species in an economical and easy to use carrier based formulation. Bioinoculants produces felicitous effects on plant growth by direct and indirect mechanism such as by phytohormone production (auxin, cytokinin or gibberallin), by enzymatic lowering of plant ethylene levels, nitrogen fixation, phosphate solubilization or by siderophores production. Bio-inoculants reintegrate the natural nutrient cycle by augmenting organic matter content and further maintain optimum nutrient level, thus results in healthy plant growth, while preserving fertility and sustainability of the soil (Shelat et al., 2017).

Despite good potentiality of microbial inoculants, the actual utilization is very low at about $2 \%$ of its potential. Meager adoption among countryman is ascribed mostly to their unpredictable response, low quality in terms of total viable counts at the time of use, short shelf life and temperature sensitiveness (Yadav \& Chandra, 2014). The possible scope of contamination is very huge in the case of carrier based bio-inoculants as massive sterilization does not provide the desired outcomes (Bhavya et al., 2017)

Liquid inoculants formulations could be a possible solution to the aforementioned tribulations as it contains cell protectants/ additives for promotion of lengthy shelf life and tolerance to unpropitious conditions of the desired microorganisms in addition to their growth nutrients (Hegde, 2008). The contamination can be managed by means of proper sterilization techniques and maintenance of rigorous hygiene conditions by appropriate quality control measures in the case of liquid based biofertilizer (Bhavya et al., 2017). Depending upon the ability to heat transfer, high water activities and rheological properties of different polymers like polyethylene glycol (Temprano et al., 2002), polyvinyl alcohol (Deaker et al., 2004), gum Arabic (Mugnier \& Jung, 1985), polyvinyl pyrrolidone (Singleton, 2002) and sodium alginate (Bashan et al., 2004) have been used for inoculants production.

Liquid inoculants can be comfortably adjusted to modish seeding equipments as it can be sprayed onto the seed as it passes through the seed auger and dries before it travels into the seed bin on the planter. The mean life of the microbes in liquid inoculants is higher without ample loss in cell counts than carrier based inoculants. They are further resistant to ultra violet radiations and high temperatures (Santhosh, 2015).

Further, the global market for microbial inoculants/ biofertilizer is expected to exceed a market worth of USD 10.2 billion by 2018 (Raja, 2013). Keeping foresaid points in view present investigation was carried out with the object to develop liquid inoculants containing Azotobacter sp. and Streptomyces badius for wheat using poly ethylene glycol @ 2\% in basal medium respectively and its comparison with charcoal carrier based inoculants under field condition.

\section{Materials and Methods}

\subsection{Procurement of standard cultures}

Standard cultures of Azotobacter sp. and Streptomyces badius were procured from Department of Microbiology, Punjab Agricultural University, Ludhiana, Punjab, India.

\subsection{Maintenance of cultures}

Azotobacter sp. and Streptomyces badius were maintained at $4^{\circ} \mathrm{C}$ in Jensen's medium and Starch casein agar medium respectively and subcultured once in a month throughout the period of investigation.

\subsection{Characterization of Azotobacter sp. and Streptomyces badius for plant growth promoting traits}

Characterization of cultures for the PGP traits were executed by the following method

\begin{tabular}{|ll|}
\hline PGP traits & Methods used \\
\hline IAA $(\boldsymbol{\mu g} / \mathbf{m l})$ & Gordon \& Werber $(1951)$ \\
\hline Phosphate solublisation $(\boldsymbol{\mu g} / \mathbf{1 0 0} \mathbf{~ m l})$ & Barrow et al. (1964) \\
\hline Siderophore production $(\boldsymbol{\mu g} / \mathbf{m l})$ & Jackson (1973) \\
\hline Gibberellic acid $(\boldsymbol{\mu g} / \mathbf{m l})$ & $\begin{array}{l}\text { Arnow }(1937), \text { Csaky } \\
(1948)\end{array}$ \\
\hline Ammonia production $(\boldsymbol{\mu m o l e} / \mathbf{m l})$ & $\begin{array}{l}\text { Cappuccino \& Sherman } \\
(1992)\end{array}$ \\
\hline ACC- deaminase activity & $\begin{array}{l}\text { Govindasamy et al. } \\
(2009)\end{array}$ \\
\hline
\end{tabular}




\subsection{Preparation of mother culture}

A loopful inoculum of pure culture of Azotobacter sp. and Streptomyces badius was inoculated in sterilized $200 \mathrm{ml}$ of nutrient broth dispensed in $500 \mathrm{ml}$ flask respectively. Flasks were incubated at $28 \pm 1^{\circ} \mathrm{C}$ for $24 \mathrm{hrs}$. The growing cells of log phase were used for the further inoculation.

\subsection{Preparation of medium for liquid inoculants}

A modified nutrient broth medium composed of 5.0 gram of $\mathrm{NaCl}, 3.0$ gram of yeast extract, 5.0 gram of peptone per litre and poly ethylene glycol @ 2\% was used as basal medium for liquid inoculants formulation.

\subsection{Vial preparation}

New plastic vials of $100 \mathrm{ml}$ were filled with small volume of water and autoclaved at $121^{\circ} \mathrm{C}(15 \mathrm{psi})$ for about $15 \mathrm{~min}$.

\subsection{Preparation of liquid inoculants}

For the preparation of liquid inoculants of Azotobacter sp. and Streptomyces badius, mother culture of Azotobacter sp. and Streptomyces badius was transferred @ 1\% to each $250 \mathrm{ml}$ flask containing $100 \mathrm{ml}$ of sterilized basal medium amended with $2 \%$ PEG and each $250 \mathrm{ml}$ flask containing $100 \mathrm{ml}$ of sterilized basal medium without $2 \%$ PEG (control). All the flasks were kept on shaker at $28 \pm 1^{\circ} \mathrm{C}$ for $24 \mathrm{hrs}$. These $\log$ phase cells were transferred into the sterilized $100 \mathrm{ml}$ capacity plastic vials under aseptic conditions after removing the water from the vials. The plastic vials containing liquid inoculants were stored in two sets viz. first set was stored at room temperature while second was stored in a refrigerator (Figure 1).

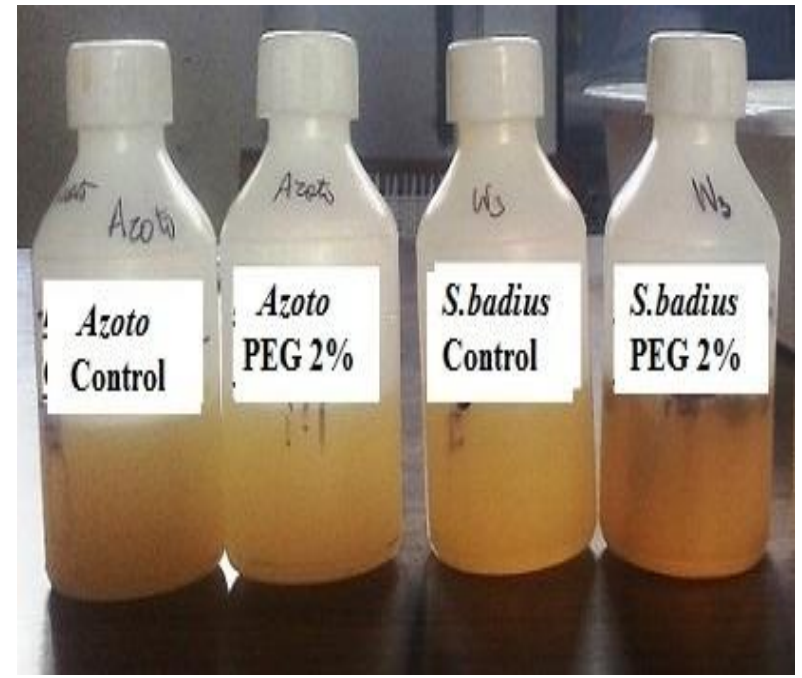

Figure 1 Plastic vials with liquid inoculants

\subsection{Preparation of charcoal carrier based inoculants}

Charcoal carrier was obtained from the Department of Microbiology, PAU, Ludhiana, India. The charcoal based formulation was prepared by mixing the broth culture of respective culture with charcoal powder at 1: 2.5 ratio. (Figure 2)
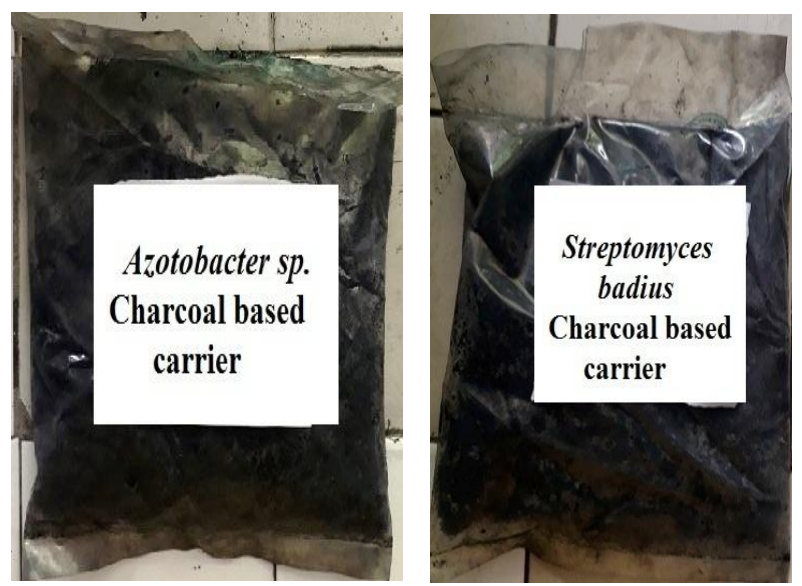

Figure 2 Charcoal based carrier inoculants

Broth culture of Azotobacter sp. and Streptomyces badius was prepared by inoculating loopful inoculums of pure culture of Azotobacter sp. and Streptomyces badius in sterilized $200 \mathrm{ml}$ of nutrient broth dispensed in $500 \mathrm{ml}$ flask respectively. The total viable count in charcoal carrier based microbial inoculants was determined by adding 10 grams of inoculant to $90 \mathrm{ml}$ of sterilized distilled water and making a 10 -fold dilution series. Then, $0.1 \mathrm{ml}$ aliquots of the appropriate dilutions were pour plate on jensen's medium and starch casein agar medium respectively at $0,30,60$, 90, 120, 150 and $180^{\text {th }}$ day. Colonies were counted after incubation of three days at $28 \pm 2{ }^{\circ} \mathrm{C}$.

\subsection{Shelf life studies of liquid inoculants at room temperature} and refrigerated temperature

The plastic vials containing liquid inoculants of Azotobacter sp. and Streptomyces badius were stored in two sets. First set was stored at room temperature while other one was stored in a refrigerator. One $\mathrm{ml}$ of sample was drawn aseptically at $0,30,60$, $90,120,150$ and $180^{\text {th }}$ day for taking total viable count by dilution pour plate method and plates were incubated at $28 \pm 2^{\circ} \mathrm{C}$ for $48-72 \mathrm{hrs}$.

\subsection{Effect of liquid inoculants on wheat under field conditions}

To evaluate the efficacy of inoculants of Azotobacter sp. and Streptomyces badius on wheat, a field experiment was conducted

Journal of Experimental Biology and Agricultural Sciences http://www.jebas.org 
with three treatments i.e. RDF, RDF + Liquid inoculants of Azotobacter sp. and Streptomyces badius and RDF + Charcoal carrier based inoculants of Azotobacter sp. and Streptomyces badius

The field experiment was conducted during winter (rabi) season of 2016-17 at Punjab Agricultural University, Regional Research Station, Bathinda, Punjab ( $30^{\circ} 09^{\prime \prime} 36^{\prime} \mathrm{N}$ latitude, $74^{\circ} 55^{\prime \prime} 28^{\prime} \mathrm{E}$ longitude; $211 \mathrm{~m}$ above sea level). The field experiment was laid out in RCBD and replicated thrice.

Wheat cultivar 'HD 3086' seeds were sown manually as per treatment schedule. The sowing was made with row to row spacing of $22.0 \mathrm{~cm}$ with the plot dimensions of $5 \mathrm{~m} \mathrm{X} 2.60 \mathrm{~m}$. Seed bacterization was done with liquid inoculants of Azotobacter sp. and Streptomyces badius @ 100ml/40kg respectively for liquid inoculants and 250 gram of charcoal carrier based inoculants of Azotobacter sp. and Streptomyces badius respectively per $40 \mathrm{~kg}$ of wheat seeds. Inoculated seeds were air dried in shade at room temperature and planted within $2 \mathrm{hrs}$. The recommended dose of $\mathrm{N}$ : P: K was applied through urea, DAP and MOP respectively. The whole of the phosphorus and potassium was applied at the time of sowing along with half of nitrogen and remaining nitrogen was applied at crown root initiation (CRI) and ear initiation (EI) stages of the crop in two splits respectively. Weeding and hoeing was done to avoid weeds and suitable control measures were taken to prevent insects and pests. A total of 3 to 4 irrigations were applied i.e first irrigation was given at 21 DAS and thereafter the experiment plots were irrigated every 25 to 30 days until the end of the season,

The net plot was harvested manually at the physiological maturity by cutting plants near ground surface after leaving the border rows. The plant were dried and weighed for biomass as well as for grain yield. The experimental data collected on various aspects of investigation were statistically analyzed with the procedure as described by Coachran \& Cox (1967). The comparisons were made at $5 \%$ level of significance.

\section{Results and Discussion}

3.1 Characterization of Azotobacter sp. and Streptomyces badius for plant growth promoting attributes

Plant growth promoting rhizobacteria (PGPR) are heterogenous group of bacteria that can be found in rhizosphere and capable of improving the extent or quality of plant growth directly or indirectly (Shahzadi et al., 2012). Rhizobacteria are now being used worldwide as bio-inoculants to promote plant growth and development under various stress conditions. Plant growth promoting attributes are important characteristic of PGPR, which influence plant growth.
In present study, the quantity of IAA, phosphate solublization, gibberellic acid and ammonia production by Azotobacter sp. was $10.75 \mu \mathrm{g} / \mathrm{ml}, 21.74 \mu \mathrm{g} / 100 \mathrm{ml}, 77.86 \mu \mathrm{g} / \mathrm{ml}$ and $27.68 \mu \mathrm{mole} / \mathrm{ml}$ respectively and by Streptomyces badius was $13.39 \mu \mathrm{g} / \mathrm{ml}, 28.73$ $\mu \mathrm{g} / 100 \mathrm{ml}, 108.44 \mu \mathrm{g} / \mathrm{ml}$ and $32.48 \mu \mathrm{mole} / \mathrm{ml}$ respectively. The siderophore production was exhibited by Streptomyces badius only. It produced $104.89 \mu \mathrm{g} / \mathrm{ml}$ of catechol type and $62.84 \mu \mathrm{g} / \mathrm{ml}$ of hydroxamate type siderophores. Both the cultures were also found positive for ACC-deaminase activity (Table 1). Thus, both Azotobacter sp. and Streptomyces badius could play important role in crop plant growth and development. Doran \& Zeiss (2000) also reported that Azotobacter can boost crop production under different stress circumstances for agriculture sustainability. Therefore there is an indispensable demand to characterize such bacterial inoculants. Similarly Streptomyces and other actinobacteria are surprisingly under explored for plant growth promotion as compared to Pseudomonas or Bacillus spp. (Doumbou et al., 2001).

Table 1 Evaluation of plant growth promoting traits of Azotobacter sp. and Streptomyces badius

\begin{tabular}{|cccc|}
\hline \multicolumn{2}{|c}{ Microbial cultures } & $\begin{array}{c}\text { Azotobacter } \\
\text { sp. }\end{array}$ & $\begin{array}{c}\text { Streptomyces } \\
\text { badius }\end{array}$ \\
\hline $\begin{array}{c}\text { IAA } \\
\text { production } \\
(\boldsymbol{\mu g} / \mathbf{m l})\end{array}$ & With tryptophan & $30.27 \pm 1.7$ & $42.09 \pm 2.8$ \\
\cline { 2 - 4 } & Without tryptophan & $10.75 \pm 0.36$ & $13.39 \pm 0.83$ \\
\hline Phosphate solublization $(\boldsymbol{\mu g} / \mathbf{1 0 0 m l})$ & $21.74 \pm 0.4$ & $28.73 \pm 0.4$ \\
\hline $\begin{array}{c}\text { Siderophore } \\
\text { production } \\
(\boldsymbol{\mu g g} / \mathbf{m l})\end{array}$ & Catechol type & - & $104.89 \pm 2.3$ \\
\cline { 2 - 4 } & Hyroxamate type & - & $62.84 \pm 0.5$ \\
\hline Gacid production $(\boldsymbol{\mu g} / \mathbf{m l})$ & $77.86 \pm 1.4$ & $108.44 \pm 1.5$ \\
\hline Ammonia production $(\boldsymbol{\mu m o l e} / \mathbf{m l})$ & $27.68 \pm 0.7$ & $32.48 \pm 1.6$ \\
\hline \multicolumn{2}{|c|}{ ACC deaminase } & + & + \\
\hline
\end{tabular}

Values are the mean of three replications $\pm \mathrm{SE}$

\subsection{Survival of liquid inoculants}

In present study the liquid inoculants were prepared by inoculating Azotobacter sp. and Streptomyces badius in basal broth medium amended with $2 \%$ poly ethylene glycol respectively. The liquid inoculants were analyzed for their survival at room temperature and refrigeration temperature over a period of six months through serial dilution pour plate method on jensen's and starch casein agar respectively.

\subsubsection{Shelf life studies of liquid inoculant of Azotobacter sp.}

The data pertaining to survivability of Azotobacter sp. in liquid inoculants without PEG $\left(\mathrm{AT}_{1}\right)$, liquid inoculants with $2 \%$ of PEG 
Table 2 Survival of Azotobacter sp. in liquid inoculants at room and refrigerated temperature and its comparison with charcoal based inoculants

\begin{tabular}{|c|c|c|c|c|c|c|c|c|}
\hline \multirow[t]{2}{*}{ Treatments } & \multicolumn{8}{|c|}{$\begin{array}{l}\text { Population density } \log _{10} \text { cfu/ml } \\
\text { Total viable count days after storage }\end{array}$} \\
\hline & 0 & 30 & 60 & 90 & 120 & 150 & 180 & $\mathrm{CD}(\mathrm{p}=0.05)$ \\
\hline $\mathbf{A} \mathbf{T}_{1}$ & $11.86 \pm 0.9$ & $10.61 \pm 1.0$ & $9.89 \pm 0.8$ & $8.29 \pm 0.6$ & $7.28 \pm 0.6$ & $5.17 \pm 0.4$ & $3.09 \pm 0.2$ & 2.26 \\
\hline $\mathbf{A} \mathbf{T}_{2}$ & $11.78 \pm 0.9$ & $11.88 \pm 0.9$ & $11.73 \pm 0.9$ & $10.89 \pm 0.8$ & $10.77 \pm 0.8$ & $10.66 \pm 0.8$ & $10.36 \pm 0.8$ & NS \\
\hline$* \mathbf{A T}_{3}$ & $10.93 \pm 1.0$ & $11.30 \pm 0.9$ & $9.88 \pm 0.9$ & $9.75 \pm 0.9$ & $9.59 \pm 0.9$ & $9.11 \pm 0.8$ & $7.90 \pm 0.7$ & NS \\
\hline $\mathbf{L A T}_{1}$ & $11.48 \pm 1.0$ & $11.38 \pm 0.9$ & $10.83 \pm 1.0$ & $10.28 \pm 0.8$ & $7.47 \pm 0.6$ & $6.25 \pm 0.5$ & $5.72 \pm 0.5$ & 2.47 \\
\hline LAT $_{2}$ & $12.38 \pm 1.1$ & $12.14 \pm 1.0$ & $11.82 \pm 1.0$ & $11.57 \pm 0.9$ & $11.20 \pm 0.9$ & $11.39 \pm 1.0$ & $11.30 \pm 1.0$ & NS \\
\hline${ }^{*} \mathbf{L A T}{ }_{3}$ & $12.25 \pm 1.1$ & $11.32 \pm 0.9$ & $11.25 \pm 1.0$ & $11.06 \pm 0.9$ & $10.17 \pm 0.8$ & $10.12 \pm 0.1$ & $9.89 \pm 0.9$ & NS \\
\hline
\end{tabular}

* $\log _{10}$ no. of cell/g, Values are the mean of three replications \pm SE; NS $=$ Non significant at $5 \%$ level of significance

$A T_{I}$ : Liquid Inoculants of Azotobacter sp. without PEG $2 \%$ at room temperature;

$A T_{2}: \quad$ Liquid Inoculants of Azotobacter sp. with $2 \%$ Polyethylene glycol at room temperature;

$A T_{3}: \quad$ Charcoal carrier based inoculants of Azotobacter sp. at room temperature;

$L A T_{1}$ : Liquid Inoculants of Azotobacter sp. without PEG $2 \%$ at refrigerated temperature;

$L A T_{2}:$ Liquid Inoculants of Azotobacter sp. with $2 \%$ Polyethylene glycol at refrigerated temperature;

$L A T_{3}: \quad$ Charcoal carrier based inoculants of Azotobacter sp. at refrigerated temperature

$\left(\mathrm{AT}_{2}\right)$ and in charcoal carrier based inoculants $\left(\mathrm{AT}_{3}\right)$ at room temperature has been presented in Table 2 and Figure 3a. The perusal of data indicated that viable count of liquid inoculants of Azotobacter sp. without PEG decreased significantly at $5 \%$ level where as viable count of liquid inoculants with $2 \%$ of PEG $\left(\mathrm{AT}_{2}\right)$ and in charcoal carrier based inoculants $\left(\mathrm{AT}_{3}\right)$ at room temperature decreased non significantly at $5 \%$ level of significance.

Initial viable count of Azotobacter sp. was $11.86 \log _{10}$ viable cells which reduced to $3.09 \log _{10}$ viable cells at $180^{\text {th }}$ day (with decrease of 73.94 per cent) in liquid inoculants without PEG $\left(\mathrm{AT}_{1}\right)$. In liquid inoculants amended with $2 \%$ of PEG $\left(\mathrm{AT}_{2}\right)$ initial count was $11.78 \log _{10}$ viable cells which further reduced to 10.36 $\log _{10}$ viable cells at $180^{\text {th }}$ day (with decrease of 12.05 per cent). In charcoal carrier based inoculants, $10.93 \log _{10}$ no. of viable cells were observed initially, the count declined to $7.90 \log _{10}$ viable cells at $180^{\text {th }}$ day after storage at room temperature (with decrease of 27.72 per cent).

The data pertaining to survivability of Azotobacter sp. in liquid inoculants without PEG $\left(\mathrm{LAT}_{1}\right)$, liquid inoculants with $2 \%$ of PEG $\left(\mathrm{LAT}_{2}\right)$ and in charcoal carrier based inoculants $\left(\mathrm{LAT}_{3}\right)$ at refrigerated temperature has been presented in Table 2 and Figure $3 \mathrm{~b}$. There was a significant effect $(\mathrm{p}=0.05)$ of storage time on viable count of liquid inoculants of Azotobacter sp. without PEG where as non significant effect on viable count of liquid inoculants with $2 \%$ of PEG $\left(\mathrm{LAT}_{2}\right)$ and charcoal carrier based inoculants $\left(\mathrm{LAT}_{3}\right)$ was observed at refrigerated temperature. Initially $12.38 \log _{10}$ viable cells in liquid inoculants amended with

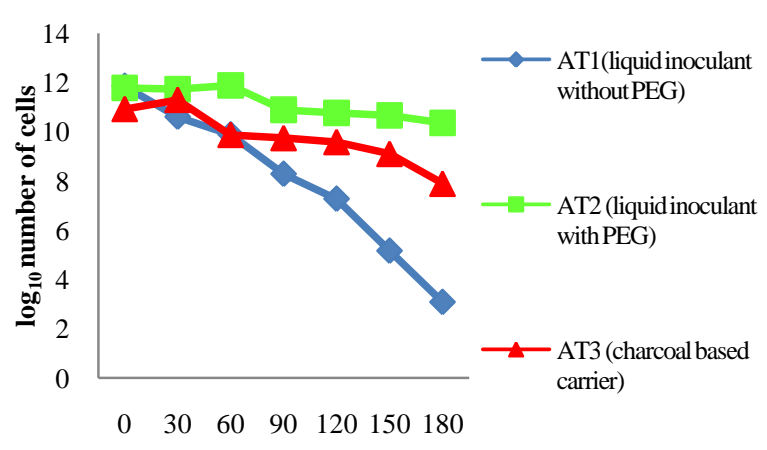

Days after storage

3(a)

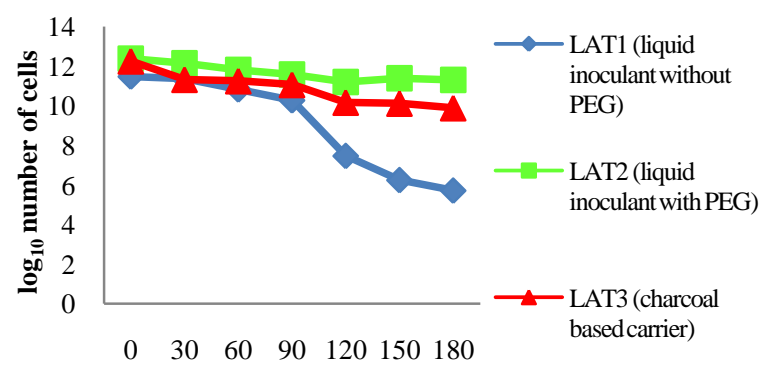

Days after storage

3(b)

Figure 3 Survival of Azotobacter sp. inoculants at room temperature (a) and refrigerated temperature (b) 
Table 3 Survival of Streptomyces badius in liquid inoculants at room and refrigeration temperature and its comparison with charcoal based inoculants

\begin{tabular}{|c|c|c|c|c|c|c|c|c|}
\hline \multirow[t]{2}{*}{ Treatments } & \multicolumn{8}{|c|}{$\begin{array}{l}\text { Population density }\left(\log _{10} \mathrm{cfu} / \mathrm{ml}\right) \\
\text { Total viable count days after storage }\end{array}$} \\
\hline & 0 & 30 & 60 & 90 & 120 & 150 & 180 & $\mathrm{CD}(\mathrm{p}=0.05)$ \\
\hline $\mathbf{S T}_{1}$ & $11.89 \pm 1.1$ & $10.19 \pm 0.8$ & $8.86 \pm 0.8$ & $8.1 \pm 0.7$ & $7.28 \pm 0.6$ & $4.20 \pm 0.4$ & $2.17 \pm 0.2$ & 2.10 \\
\hline $\mathrm{ST}_{2}$ & $11.76 \pm 0.95$ & $11.81 \pm 1.1$ & $11.67 \pm 0.9$ & $10.25 \pm 0.8$ & $10.18 \pm 0.8$ & $10.12 \pm 0.8$ & $10.35 \pm 0.8$ & NS \\
\hline$* \mathbf{S T}_{3}$ & $11.82 \pm 1.1$ & $11.30 \pm 0.9$ & $11.25 \pm 0.9$ & $9.19 \pm 0.8$ & $8.46 \pm 0.7$ & $9.33 \pm 0.8$ & $6.86 \pm 0.6$ & 2.63 \\
\hline $\mathbf{L S T}_{1}$ & $12.09 \pm 1.0$ & $11.99 \pm 1.1$ & $10.79 \pm 0.8$ & $8.07 \pm 0.7$ & $7.89 \pm 0.6$ & $6.41 \pm 0.5$ & $5.29 \pm 0.5$ & 2.40 \\
\hline $\mathrm{LST}_{2}$ & $11.83 \pm 1.1$ & $12.21 \pm 1.0$ & $12.14 \pm 1.1$ & $11.07 \pm 0.9$ & $10.98 \pm 0.9$ & $10.61 \pm 1.0$ & $10.57 \pm 1.0$ & NS \\
\hline${ }^{*} \mathbf{L S T}_{3}$ & $10.88 \pm 1.0$ & $12.14 \pm 1.0$ & $12.06 \pm 1.1$ & $10.83 \pm 0.8$ & $10.23 \pm 0.8$ & $8.35 \pm 0.7$ & $8.21 \pm 0.7$ & 2.77 \\
\hline $\begin{array}{ll}* \log _{10} & \text { no. of cel } \\
\text { ST 1 : } & \text { Liquid } \\
\text { ST 2 : } & \text { Liquid } \\
\text { ST 3 : } & \text { Charc } \\
\text { LST 1: } & \text { Liquid } \\
\text { LST 2: } & \text { Liquid } \\
\text { LST 3 : } & \text { Charc }\end{array}$ & $\begin{array}{l}\text { Values are the } \\
\text { culants of Stre } \\
\text { culants of Stre } \\
\text { arrier based it } \\
\text { culants of Stre } \\
\text { culants of Stre } \\
\text { arrier based it }\end{array}$ & $\begin{array}{l}\text { ean of three r } \\
\text { omyces badiu } \\
\text { omyces badiu } \\
\text { culants of Str } \\
\text { omyces badiu } \\
\text { omyces badiu } \\
\text { culants of Str }\end{array}$ & $\begin{array}{l}\text { lications } \pm \mathrm{SE} \\
\text { without PEG } \\
\text { with } 2 \% \text { Poly } \\
\text { tomyces bad } \\
\text { without PEG } \\
\text { with } 2 \% \text { Poly } \\
\text { tomyces bad }\end{array}$ & $\begin{array}{l}\mathrm{NS}=\text { Non sig } \\
\% \text { at room ten } \\
\text { hylene glycol } \\
\text { s at room tem } \\
\% \text { at refrigerd } \\
\text { hylene glycol } \\
\text { s at refrigera }\end{array}$ & $\begin{array}{l}\text { ficant at } 5 \% 1 \\
\text { erature } \\
\text { room temperc } \\
\text { rature } \\
\text { d temperature } \\
\text { refrigerated } t \\
\text { temperature }\end{array}$ & $\begin{array}{l}\text { el of signific } \\
\text { ure } \\
\text { nperature }\end{array}$ & & \\
\hline
\end{tabular}

PEG 2\% ( $\left.\mathrm{LAT}_{2}\right)$ which further reduced to $11.30 \log _{10}$ viable cells at $180^{\text {th }}$ day. In charcoal carrier based inoculants $\left(\mathrm{LAT}_{3}\right)$, initial count was $12.25 \log _{10}$ viable cells that declined to $9.89 \log _{10}$ viable cells at $180^{\text {th }}$ day (with reduction of 19.26 percent). The minimum $\log _{10}$ viable cells were recorded in liquid inoculants without PEG ( $\left.\mathrm{LAT}_{1}\right)$. The initial count (11.48 $\log _{10}$ viable cells) reduced to $5.72 \log _{10}$ viable cells at $180^{\text {th }}$ day (with reduction of 50.17 percent). Higher survival of respective inoculants at refrigerated conditions may be due to the fact that freezing temperature slows down the decomposition of nutrients by turning residual moisture into ice thus inhibiting the growth of most of the bacteria.

Overall findings in present study were in line with Dayamani \& Brahmaprakash (2014) who demonstrated that media amended with PEG 400 at all concentrations, PEG 600 and PEG 6000 at the $2 \%$ level and glycerol at the $0.5 \%$ level increased population density substantially. Similar findings were reported by Kumaresan \& Reetha, (2011) who concluded that liquid Azospirillum bio-inoculants with poly ethylene glycol (1\%), poly vinyl alcohol $(0.5 \%)$ and control (lignite carrier) recorded the same population of $10^{8}$ cells ml ${ }^{-1}$ upto 8 months, 6 months and 5 months of storage respectively under ambient temperature $\left(28^{\circ} \mathrm{C}\right.$ to $\left.32^{\circ} \mathrm{C}\right)$.

Thus amendment of liquid inoculants with poly ethylene glycol (PEG) enhances shelf life of liquid inoculants because of its viscous nature that may slow down the drying process and its sticky consistency which further reinforce culture attachment to seed (Temprano et al., 2002).

\subsubsection{Shelf life studies of liquid inoculant of Streptomyces badius}

The perusal of data in Table 3 indicated that at room temperature, the liquid inoculants amended with PEG 2\% ( $\left.\mathrm{ST}_{2}\right)$ supported better viability as compared to liquid broth without PEG $2 \%\left(\mathrm{ST}_{1}\right)$ and charcoal based carrier $\left(\mathrm{ST}_{3}\right)$. There was non significant $(\mathrm{p}=0.05)$ effect of storage time on viable count of liquid inoculants amended with PEG $2 \%\left(\mathrm{ST}_{2}\right)$ at room temperature. Initially $11.89 \log _{10}$ viable cells were observed in liquid inoculants without PEG ( $\left.\mathrm{ST}_{1}\right)$ which decreased to $2.17 \log _{10}$ viable cells at $180^{\text {th }}$ day at room temperature. This may be due the achievement of stationary phase and desiccation of cells. The liquid inoculants amended with $2 \%$ PEG, initially showed $11.76 \log _{10}$ viable cells which decreased to $10.35 \log _{10}$ viable cells at $180^{\text {th }}$ day (with decrease of 11.98 per cent) followed by charcoal based carrier microbial inoculants of Streptomyces badius $\left(\mathrm{ST}_{3}\right)$ with $11.82 \log _{10}$ viable cells initially which decreased to $6.86 \log _{10}$ viable cells (with decrease of 41.96 per cent) at $180^{\text {th }}$ day (Figure $4 a$ ).

Similarly, perusal of data at refrigerated temperature indicated that liquid inoculants of Streptomyces badius with PEG 2\% $\left(\mathrm{LST}_{2}\right)$ showed the highest count $\left(10.57 \log _{10}\right.$ viable cells $)$ at $180^{\text {th }}$ days which was followed by charcoal carrier based inoculants (8.21 $\log _{10}$ viable cells) at $180^{\text {th }}$ days and least count was observed in liquid inoculants without PEG 2\% (5.29log 10 viable cells) at refrigerated temperature. The liquid inoculants of Streptomyces badius with PEG 2\% ( $\left.\mathrm{LST}_{2}\right)$ showed non significant $(\mathrm{p}=0.05)$ decrease in viable count (Figure $4 \mathrm{~b}$ ). Higher survival under refrigerated conditions might be due to little growth with little 


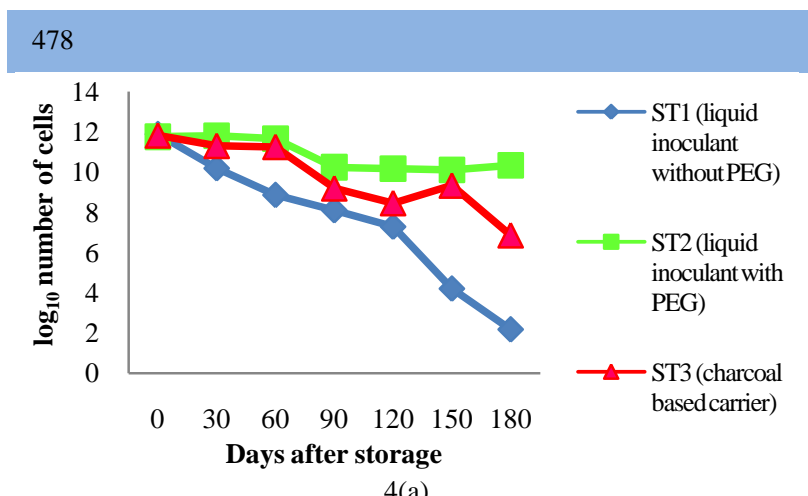

4(a)

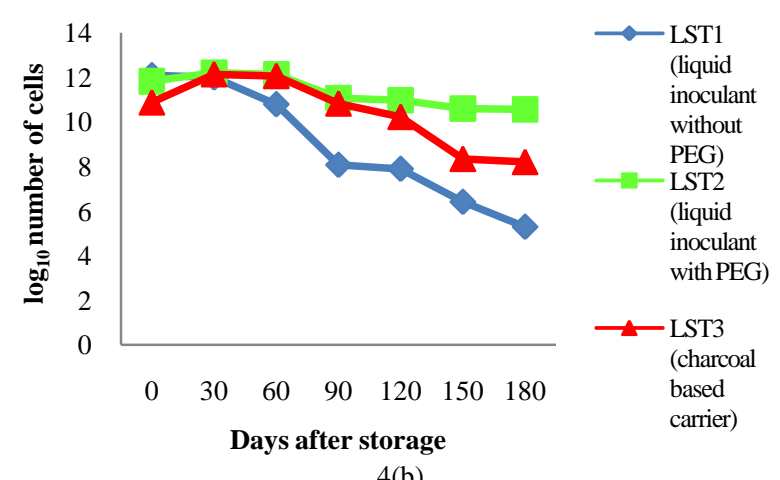

Figure 4 Survival of Streptomyces badius inoculants at room temperature (a) and refrigerated temperature (b)

utilization of nutrients during storage make the availability of nutrients to the organism in optimum concentration for longer period. Low temperature in refrigerator also protects the cell death in inoculums. In contrast, during storage at room conditions where temperature reached beyond $30^{\circ} \mathrm{C}$, growth of organism results in creating depletion of nutrients and accumulation of toxic metabolites (Maurice et al., 2001). Desiccation and high temperature also influence the survival of cells on the seeds (Tittabutr et al., 2007; Daniel et al., 2013).

Thus overall highest viable count of Streptomyces badius was observed in liquid inoculants amended with $2 \%$ of PEG followed by charcoal carrier based inoculants and lowest count was observed in liquid inoculants without 2\% PEG both at room temperature as well as at refrigerated temperature. The results are supported by the findings of Kumar et al. (2014) who reported a frequent decrease in viable count from $10^{9}$ to $10^{7}$ colony-forming units (cfu/g) per g after 90 days of storage. Temprano et al. (2002) further reported that poly ethylene glycol prevents the microbial inoculants from desiccation due to its viscosity which slow down the process of drying process. Moreover PEG is a synthetic polymer approved by the FDA for internal consumption and injection in a variety of foods, cosmetics and drug delivery systems (Cavalla, 2001).

\subsection{Effect of liquid inoculants on wheat under field conditions}

The second most predominant cereal crop in India after rice is wheat. Wheat provides more than 50 per cent of calories to the people who mainly dependent on it and contributing considerably to the national food security. To fulfill the food supply requirements for projected population by 2050 significant increase (an estimated 50\%) in grain yield of major crop plants like rice (Oryza sativa L.), wheat (Triticum aestivum L.) and maize (Zea mays L.) is mandatory (Godfray et al., 2010).

Diverse PGPRs have been used worldwide as microbial inoculants, contributing to increasing crop yields and soil fertility and hence with potential to contribute to more sustainable agriculture and forestry (García-Fraile et al., 2015). During the past two decades the practice of microbial inoculants in agriculture has increased incredibly (Hayat et al., 2010) due to public and private sector agricultural research and development communities which are working for solutions to tribulations associated with contemporary agriculture. There are considerable advantages of liquid inoculants such as no contamination, huge cell count, lengthy shelf life, higher stability against environmental stress and increased field efficacy (Tittabutr et al., 2007; Liu et al., 2009). For evaluating the effect of liquid formulation of inoculants viz. Azotobacter sp. and Streptomyces badius on yield attributes of wheat and comparison with charcoal carrier based inoculants of Azotobacter sp. and Streptomyces badius an experiment was conducted at PAU, RRS, Bathinda during rabi 2016-17. The results of the study were discussed under following headings.

\subsubsection{Grain Yield}

Grain yield in wheat is primarily a function of effective tillers number of spikes, number of grains per spike, spike length and thousand grain weight. The data pertaining to grain yield of wheat as influenced by liquid inoculants and charcoal carrier based inoculants of Azotobacter sp. and Streptomyces badius has been presented in Table 4. The perusal of data indicated that application of microbial inoculants of Azotobacter sp. and Streptomyces badius had not any significant effect on grain yield of wheat at $5 \%$ level of significance. However, highest grain yield was observed with liquid inoculants followed by charcoal carrier based inoculants. Son et al. (2006) also observed enhanced grain yield, nutrient availability and uptake in soybean crop (Glycine max) by the application of liquid PSB inoculants. Similar results were observed by Nezarat \& Gholami (2009) who found increase in the yield of wheat upto $30 \%$ by the use of combined inoculation of Azotobacter and PSB over control. Poly ethylene glycol 
Table 4 Grain yield and biological yield of wheat crop as affected by inoculants

\begin{tabular}{|cccc|}
\hline S.No & Treatments & Grain Yield (t/ha) & Biological Yield (t/ha) \\
\hline 1 & RDF & 5.01 & 14.55 \\
\hline 2 & $\begin{array}{c}\text { RDF + Liquid inoculants of Azotobacter } \text { sp. }+ \\
\text { Streptomyces badius }\end{array}$ & 5.14 & 15.70 \\
\hline 3 & $\begin{array}{c}\text { RDF + Charcoal carrier based inoculants of } \\
\text { Azotobacter } \text { sp. }+ \text { Streptomyces badius }\end{array}$ & 5.13 & 15.29 \\
\hline & $\mathrm{CD}(\mathrm{p}=0.05)$ & $\mathrm{NS}$ & $\mathrm{NS}$ \\
\hline
\end{tabular}

NS $=$ Non significant at $5 \%$ level of significance

prevents the microbial inoculants from desiccation due to its viscosity which slow down the drying process (Temprano et al., 2002). These might be the mechanisms that improves the survival of cells on the seeds and give rise to more plant growth.

\subsubsection{Biological Yield}

Biological yield represents the total biomass of plant organs and effective absorption of nutrient elements. The data pertaining to biological yield has been presented Table 4. The highest biological yield was produced with liquid inoculants (15.70 t/ha), followed by carrier based inoculants (15.29 t/ha) whereas lowest biological yield were recorded with control $(14.55 \mathrm{t} / \mathrm{ha})$. This might be because of nitrogen fixing, phosphate solubilization and ACC deaminase activity of inoculated culture i.e Azotobacter sp. and Streptomyces badius in the form of microbial inoculants. Similarly, enhancement in grain yield $(16.3 \%)$ was reported by Lakshminarayana et al. (2000) with inoculation of Azotobacter chroococcum strain A103 in wheat variety WH291.The Plant growth promoting potential of Streptomyces was also reported on wheat by Sadeghi et al. (2012).

However, application of microbial inoculants of Azotobacter sp. and Streptomyces badius had not any significant effect on biological yield of wheat at 5\% level of significance but better respond was observed with liquid inoculants. The percentage increase in biological yield with application of liquid inoculants was 7.87 percent. This might be due to higher survival of Azotobacter sp. and Streptomyces badius in liquid formulation. Brahmaprakash \& Sahu (2012) also reported that the population density of Acinetobacter was highest in the presence of PEG.

\section{Conclusion}

Liquid inoculants as well as charcoal carrier based inoculants of Azotobacter sp. and Streptomyces badius were found to enhance yield attributing characters of wheat under field conditions by direct and indirect mechanisms such as biological nitrogen fixation, phosphate solubilization, phytohormones production and ACC deaminase activity, siderophore production. However, liquid inoculants of Azotobacter sp. and Streptomyces badius were found to be superior over charcoal carrier based inoculants. This might be due to higher survival of Azotobacter sp. and Streptomyces badius in liquid formulation.

\section{Conflict of Interest}

Authors declare that there is no conflict of interests arising from this study.

\section{References}

Arnow LE (1937) Colorimetric estimation of the components of 3,4-dihydroxy phenylalanine tyrosine mixtures. Journal of Biological Chemistry 118: 513-535.

Bashan Y, Holguin G, de-Bashan LE (2004) Azospirillum-plant relationships: physiological, molecular, agricultural and environmental advances (1997- 2003). Canadian Journal of Microbiology 50: 521-577.

Barrow A, Brown S, Jefferys EG, Kessell RJ, Lloyd EC, Lloyd PB, Rothwell B, Swait JC (1964) The kinetics of metabolism of Gibberella fujikuroi in stirred culture. Canadian Journal of Microbiology 10: 407-444.

Bhavya K, Subhash Reddy R, Triveni S, Damodara Chari K, Nagaraju Y (2017) Study of Shelflife of Carrier Biofertilizers from Different Production Centers. International Journal of Current Microbiology and Applied Sciences 6: 1776-1783.

Brahmaprakash GP, Sahu PK (2012) Biofertilizers for Sustainability. Journal of Indian Institute of Science 92: 37-61.

Cappuccino JC, Sherman N (1992) In: Microbiology: A Laboratory Manual, New York. Academic distributors, New Delhi. Pp. 125-179.

Cavalla D (2001) Adaptations and innovations in drug delivery. Drug News and Prespectives 14: 495-499. 
Cochran WG, Cox GM (1967) Experimental designs. Asia Publishing House, Bombay.

Csaky T (1948) On the estimation of bound hydroxylamine in biological materials. Acta Chemica Scandinavica 2: 450-454.

Daniel L AE, Venkateswarlu B, Desai S, Kumar PG, Ahmed AHSK, Sultana U, Pinisetty U, Narasu LM (2013) Effect of polymeric additives, adjuvants, surfactants on survival, stability and plant growth promoting ability of liquid bio-inoculants. Journal of Plant Physiology \& Pathology 1: 1-5.

Dayamani KJ, Brahmaprakash GP (2014) Influence of form and Concentration of the Osmolytes in Liquid Inoculants Formulations of Plant Growth Promoting Bacteria. International Journal of Scientific and Research Publication 4: 1-6.

Deaker R, Roughley RJ, Kennedy IR (2004) Legume seed inoculation technology-a review. Soil Biology and Biochemistry 36: $1275-1288$

Doran JW, Zeiss MR (2000) Soil health and sustainability: managing the biotic component of soil quality. Applied Soil Ecology 15: 3-11.

Doumbou CL, Salove MKH, Crawford LD, Beaulieu C (2001) Actinomycetes, promising tools to control plant diseases and to promote plant growth. Phytoprotection 82: 85-102.

García-Fraile P, Menéndez E, Rivas R (2015) Role of bacterial biofertilizers in agriculture and forestry. AIMS Bioengineering 2: 183-205.

Godfray HCJ, Beddington JR, Crute IR, Haddad L, Lawrence D, Muir J F, Pretty J, Robinson S, Thomas SM, Toulmin C (2010) Food security: the challenge of feeding 9 billion people. Science 327: $812-818$

Gordon AS, Werber RP (1951) Calorimetric estimation of Indole acetic acid. Plant Physiology 25: 192-195.

Govindasamy V, Kumar SM, Mageshwaran V, Annapurna K (2009) Detection and characterization of ACC in plant growth promoting Rhizobacteria. Journal of Plant Biochemistry and Biotechnology 18: 71-76.

Hayat R, Ali S, Amara U, Khalid R, Ahmed I (2010) Soil beneficial bacteria and their role in plant growth promotion: a review. Annals of Microbiology 60: 579-598.

Hegde SV (2008) Liquid biofertilizers in Indian agriculture. Biofertilizer News letters 17-22.
Jackson ML (1973) Estimation of phosphorous content in Soil chemical analysis. Prentice hall, New Delhi, India. Pp 134.

Kumar A, Maurya BR, Raghuwanshi R (2014) Isolation and characterization of PGPR and their effect on growth, yield and nutrient content in wheat (Triticum aestivum L.). Biocatalysis and Agricultutral Biotechnology 3: 121-128.

Kumaresan G, Reetha D (2011) Survival of Azospirillum brasilense in liquid formulation amended with different chemical additives. Journal of Phytology 3: 48-51.

Lakshminarayana KR, Shukla B, Sindhu SS, Kumari P, Narula N, Sheoran RK (2000) Analogue resistant mutants of Azotobacter chroococcum derepressed for nitrogenase activity and early ammonia excretion having potential as inoculants for cereal crops. Indian Journal of Experimental Biology 38: 373-78.

Liu J, Tian S, Li B, Qin G (2009) Enhancing viability of two biocontrol yeasts in liquid formulation by applying sugar protectant combined with antioxidant. Biocontrol 54: 817-824.

Maurice S, Beauclair P, Giraud J, Sommer G, Hartmann A (2001) Survival and change in physiological state of Bradyrhizobium japonicum in soybean (Glycine max L. Merril) liquid inoculants after long-term storage. World Journal of Microbiology and Biotechnology 17: 635-643.

Mugnier J, Jung G (1985) Survival of bacteria and fungi in relation to water activity and the solvent properties of water in biopolymer. Applied Environmental Microbiology 50: 108-114.

Nezarat S, Gholami A (2009) Screening plant growth promoting rhizobacteria for improving seed germination, transplant growth and yield of maize. Pakistan Journal of Biological Sciences 12: 26-32.

Raja N (2013) Biopesticides and biofertilizers: ecofriendly sources for sustainable agriculture. Journal of Biofertilizers and Biopesticides 112:1000e112.

Sadeghi A, Karimi E, Dahaji PA, Javid MG, Dalvand Y, Askari H (2012) Plant growth promoting activity of an auxin and siderophore producing isolate of Streptomyces under saline soil conditions. World Journal of Microbiology and Biotechnology 28: 1503-09.

Santhosh GP (2015) Formulation and Shaelf- life of Liquid Biofertlizer Inoculant Using Cell Protectants. International Journal of Research Biosciences \& Agriculture Technology 2: 243-247.

Shahzadi N, Basharat A, Shahida H (2012) Growth promotion of Vigna mungo (L.) by Pseudomonas spp. exhibiting auxin production and ACC-deaminase activity. Annals Microbiology 62: 411-417. 
Shelat HN, Vyas RV, Jhala YK (2017) Biofertilizers and PGPR for evergreen agriculture In: Verma DK, Srivastav PP (ed) Microorganisms in Sustainable Agriculture, Food and the Environment. CRC Press, Taylor \& Francis Group.

Singleton P (2002) Development and evaluation of liquid inoculants. In: Herridge D (ed) Inoculants and nitrogen fixation of legumes in Vietnam. ACIAR Proceedings 109: 52-66.

Son TTN, Diep NC, Giang TTM (2006) Effect of Bradyrhizobia and phosphate solubilising bacteria application on soybean in rotational system in the mekong delta. Omonrice 14: 48-57.

Temprano FJ, Albareda M, Camacho M, Daza A, Santamaria C,
Rodriguez-Navarro D N (2002) Survival of several Rhizobium/Bradyrhizobium strains on different inoculants formulations and inoculated seeds. International Microbiology 5: 81-86.

Tittabutr P, Payakapong W, Teaumroong N, Singleton PW, Boonkerd N (2007) Growth, survival and field performance of Bradyrhizobial liquid inoculant formulations with polymeric additives. Science Asia 33: 69-77.

Yadav AK, Chandra K (2014) Mass Production and Quality Control of Microbial Inoculants. Proceedings of Indian National Science Academy. Spl Section 80: Pp 483-489. 